\title{
Congenital aneurysm of left atrial appendage ${ }^{\star}$
}

\author{
DEAN A BRAMLET, JESSE E EDWARDS
}

From the Department of Pathology, United Hospitals-Miller Division, St Paul, and the Departments of Medicine and Pathology, University of Minnesota, Minneapolis, USA

SUMMARY Congenital aneurysm of the left atrial appendage is a rare anomaly, usually presenting in adult life. The case reported is that of a 55-year-old man who died of cerebral embolism originating from a thrombus in a congenital aneurysm of the left atrial appendage. The cardiac silhouette 11 years previously had suggested a cardiac tumour or a pericardial cyst. As judged from 14 published cases, the major manifestations of these aneurysms are an abnormal cardiac silhouette in the $x$-ray, supraventricular tachycardia, and systemic embolism. Angiocardiography appears to be the method of choice in establishing the diagnosis. Resection of the aneurysm is the recommended form of treatment.

Aneurysmal dilatation of the left atrium in the absence of demonstrable left ventricular or mitral valvular disease is rare. Such aneurysms are considered to be of congenital origin and, though they may involve the wall of the body of the left atrium, they are more frequently confined to the left atrial appendage. Abnormal mediastinal $x$-ray silhouette is often the mode of presentation. Recognition of this condition is imperative, since life-threatening systemic embolisation and supraventricular arrhythmias are frequent complications, for which aneurysmectomy is recommended. We report a case of congenital aneurysm of the left atrial appendage which illustrates the natural history of the surgically uncorrected lesion. This is the only example of the condition in the collection of the Registry of Cardiovascular Pathology of the United Hospitals-Miller Division.

\section{Case report}

Our initial experience with this case was for the purpose of review of a specimen of heart obtained at necropsy. The medical history is reviewed chronologically.

In June 1967, a 44-year-old white man was admitted to hospital with a six months' history of worsening dyspnoea and an abnormal cardiac silhouette in the thoracic $x$-ray film. One month previously, he had been successfully treated with

$\star$ This study was supported by a Public Health Service Research Grant from the National Heart, Lung, and Blood Institute. quinidine and digitalis for a supraventricular arrhythmia. Examination then had revealed a dynamic praecordium, with a soft, systolic murmur of ejection quality at the lower left sternal border. The first heart sound was loud. Slight hepatomegaly was noted. The initial clinical differential diagnoses included cardiac tumour, pericardial cyst, and congenital deficiency of the pericardium.

At cardiac catheterisation, the cardiac output was $5.71 / \mathrm{min}$ (cardiac index of $3.01 / \mathrm{min}$ per $\mathrm{m}^{2}$ ). The pulmonary arterial pressure was $28 / 11 \mathrm{mmHg}$, and the pulmonary arterial "wedge pressure" was $5 \mathrm{mmHg}$. The left ventricular pressure was $170 / 0$, while the aortic pressure was $170 / 84 \mathrm{mmHg}$. Left ventriculography showed a mass encroaching anteriorly upon the superolateral aspect of the left ventricle displacing the anterior descending and circumflex coronary arteries downward. A right ventriculogram showed encroachment on the chamber from an extrinsic mass which did not opacify during the laevophase. The mass was felt to be unrelated to the left atrium, probably representing a cardiac tumour or pericardial cyst. Operation was not performed.

On several occasions during the next nine years, recurrent atrial fibrillation was treated with either cardioversion or digitalis and quinidine. An echocardiogram revealed an ill-defined solid density. Anticoagulation with warfarin was started in 1972 for an apparent episode of pulmonary embolism, but was stopped in 1976 (two years before death) because of alcohol abuse. 
On 17 January 1978 the patient developed sudden onset of dizziness and diplopia which progressed over 30 minutes to coma, with a disconjugate gaze and a fixed dilated right pupil. The blood pressure was $140 / 84 \mathrm{mmHg}$. No murmurs were heard. The chest $x$-ray film showed persistence of the abnormal cardiac silhouette observed earlier (Fig. 1a). The electrocardiogram (Fig. 1b) disclosed left atrial abnormality and non-specific $S T$ and $T$ wave changes with poor $R$ wave progression across the praecordium, unchanged from an earlier tracing in 1977.

The patient remained in dense coma, the course being complicated by upper gastrointestinal bleeding, Staphylococcus aureus 'septicaemia, and recurrent supraventricular larrhythmias. The 'patient died on the sixteenth hospital day.]

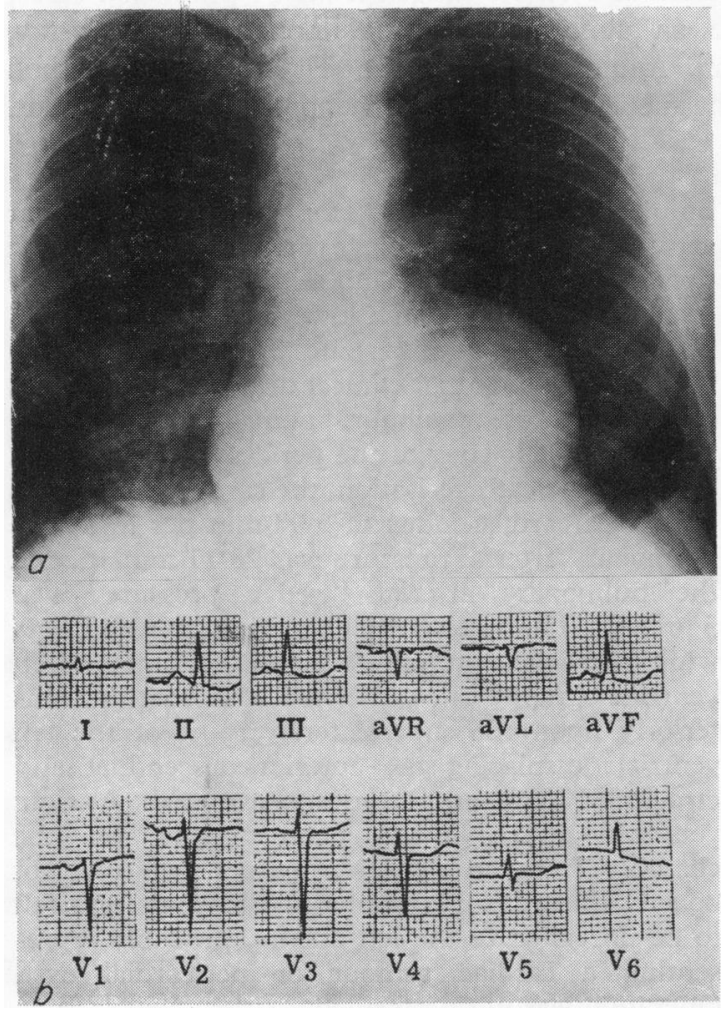

Fig 1 (a) Chest x-ray film in posteroanterior projection during final admission. There is a large, rounded mass at the left border of the cardiac silhouette corresponding to the aneurysm of the left atrial appendage. Infiltrate in right lower lung field is also present. (b) Electrocardiogram taken during final admission. There are non-specific $S T$ segment and $T$ wave changes, poor $R$ wave progression across the praecordium, and terminal negativity of $P$ waves in leads $V 1$ and $V 2$.

\section{PATHOLOGICAL FEATURES}

The pathological abnormalities at necropsy were in the left atrial appendage and brain. The pericardium was intact. The heart was slightly hypertrophied, weighing $390 \mathrm{~g}$.

A giant left atrial appendage aneurysm was found, $8 \mathrm{~cm}$ in length and $7 \mathrm{~cm}$ in diameter, with a $6 \mathrm{~cm}$ orifice (Fig. 2a and b). The aneurysm contained a large $5 \mathrm{~cm}$ thrombus partly adherent to the wall (Fig. 2c). The aneurysm rested over the anterior portion of the left ventricle and the right ventricular outflow tract, displacing and flattening the anterior descending coronary artery. The main body of the left atrium was within normal limits, as were the valves. A moderate degree of coronary atherosclerosis was present.

The central nervous system showed massive infarction of the midbrain and right cerebellar peduncle. No occluded arteries were observed. Multiple old renal infarcts were present. The lungs were emphysematous and showed bronchopneumonia, and superficial gastric ulcerations were present.

Histologically, the wall of the left atrial appendage showed a varying picture from normal thickness to gradual thinning of the myocardium and ultimate atrophy of the myocardium with fibrous replacement. The endocardium was focally thickened with collagen. The thrombus was laminated, containing leucocytes and some cavities of blood. No evidence of infection was observed.

\section{Comment}

Aneurysmal dilatation of the left atrium may be either acquired or congenital. The left atrium generally may achieve giant proportions, as in mitral regurgitation. ${ }^{1}$ Herniation of the left atrial appendage through a pericardial defect may mimic primary congenital aneurysm of the left atrial appendage. ${ }^{2} 3$ Neither of these states, however, should be considered a true aneurysm.

A true aneurysm of the left atrium is thought to represent developmental focal weakness of the left atrial wall. ${ }^{4}$ Rarely, congenital right atrial appendage aneurysms have also been reported. ${ }^{5}$ Congenital aneurysms of the left atrium may involve the left atrial wall ${ }^{6}$ or, more commonly, are confined to the left atrial appendage. This discussion will be limited to the latter.

Krueger et al. ${ }^{7}$ in reviewing published reports found 12 reported cases with aneurysm of the left atrial appendage. We found an additional two cases previously reported. ${ }^{8} 9$ The earliest reported probable case is that described by Ingram and Macfie ${ }^{8}$ 
in which the patient died suddenly from rupture of the aneurysm.

Judging from the 14 reported cases and ours, the usual modes of presentation are (1) an abnormal chest $x$-ray; (2) systemic embolisation; (3) supraventricular arrhythmias, alone or in combination. As in our patient, presenting symptoms often relate to an associated supraventricular arrhythmia and may include dyspnoea, palpitation, or thoracic pain.

The diagnosis of congenital aneurysm of the left atrial appendage has been initially suggested by the thoracic $x$-ray which shows a prominent convexity at the left basal aspect of the cardiac silhouette or "globular cardiomegaly".? In all cases in which a chest $x$-ray has been done, it was abnormal.

A low grade systolic murmur has been reported in several cases, as in our case. This is probably unrelated to the aneurysm. Only in one case has a diastolic murmur of uncertain significance been reported. ${ }^{10}$
The electrocardiogram has often been abnormal and may show supraventricular arrhythmias, interventricular conduction defects, signs of left atrial hypertrophy, and abnormalities of repolarisation. Echocardiography and radionuclide blood pool scintigraphy have helped to identify the "mass lesion" as being of cardiovascular origin.?

From reported accounts, angiocardiography has usually been the definitive method of establishing the diagnosis of aneurysm of the left atrial appendage. ${ }^{9}$ In some cases, however, the conclusion occurring after catheterisation has been left ventricular tumour or aneurysm. ${ }^{11} 12$ Obliteration of the lumen of the atrial appendage by thrombus may obscure angiocardiographic demonstration of the aneurysm.

Other congenital anomalies have only rarely been reported in association with congenital aneurysm of the left atrial appendage. These include one case each of atrial septal defect, anomaly of the renal
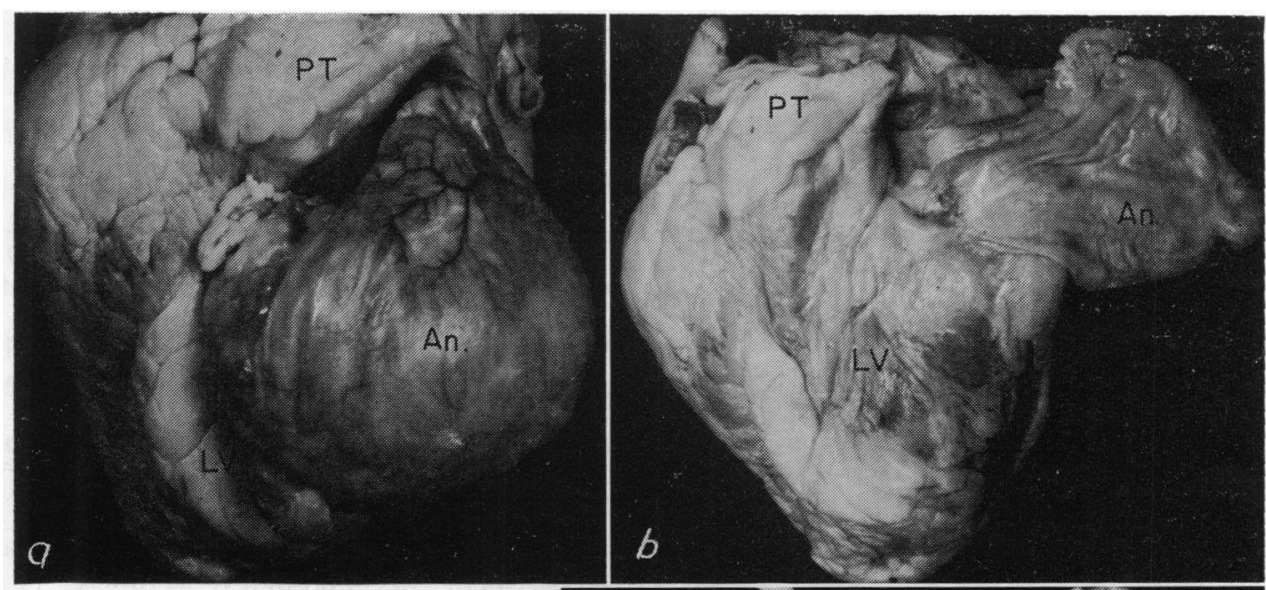

Fig. 2 Gross specimen of heart.

(a) Left anterior view. The globular mass (An) represents the aneurysm of the left atrial appendage inflated with air. Flattening of left ventricular wall ( $L V)$. PT, pulmonary trunk. (b) Perspective as shown in (a) but with aneurysm of left atrial appendage $(A n)$ deflated and reflected posteriorly. Flattening of anterolateral wall of the left ventricle (LV) is prominent. PT, pulmonary trunk. (c) Opened left atrium ( $L A$ ) and left ventricle ( $L V)$. Aneurysm of left atrial appendage ( $A n)$ contains a large thrombus $(T)$.

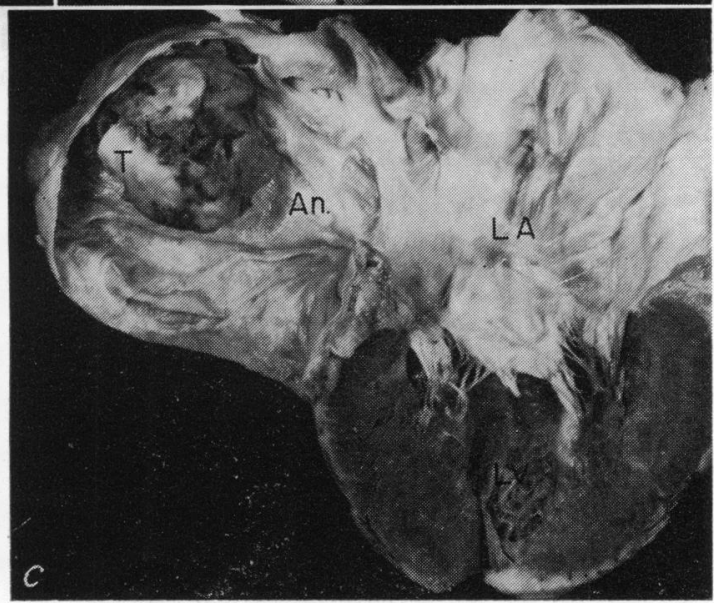


artery, and hypospadias. ${ }^{13} 14$

Recognition of a congenital aneurysm of the left atrial appendage is important prognostically, since supraventricular arrhythmias and systemic embolisation are common. ${ }^{15}$ Our case indicates the natural history of the unoperated aneurysm of the left atrial appendage. In one earlier case ${ }^{10}$ in which an aneurysmectomy was declined initially, subsequent cerebral embolisation led to reconsideration for operation. After aneurysmectomy, no further emboli occurred. In other cases, recurrent supraventricular arrhythmias have been abolished by aneurysmectomy..$^{12}{ }^{16}$ As far as we are aware, in the published reports there are nine cases in which a left atrial aneurysm has been resected. In each, good short-term results have been described.

Despite the fact that the aneurysm of the left atrial appendage is thought to be congenital in nature, most patients have few problems early in life. ${ }^{17}$ Only one-third of the patients have presented symptomatically before the age of 10 years. In most of the patients the condition has been discovered in the second to the fourth decades of life. It is likely that aneurysms of the left atrial appendage are initially small and become obvious only after years of enlargement. Stasis in the aneurysmal cavity probably accounts for the thrombosis that underlies embolisation.

At present it seems judicious to offer aneurysmectomy to an otherwise healthy patient with congenital aneurysm of the left atrial appendage as a prophylactic measure. The natural history as judged by our zase suggests that operation may prevent early mortality from systemic embolisation.

\section{References}

${ }^{1}$ DeSanctis RW, Dean DC, Bland EF. Extreme left atrial enlargement. Some characteristic features. Circulation 1964; 29: 14-23.

${ }^{5}$ Fry W. Herniation of the left auricle. Am f Surg $1953 ; 86$ : 736-8.
${ }^{3}$ Dimond EG, Kittle CF, Voth DW. Extreme hypertrophy of the left atrial appendage. The case of the giant dog ear. Am f Cardiol 1960; 5: 122-5.

${ }^{4}$ Shaher RM, Anis W, Alley R, Mintzer J. Congenital enlargement of the left atrium. $\mathcal{F}$ Thorac Cardiovasc Surg 1972; 63: 292-9.

${ }^{5}$ Sheldon WC, Johnson CD, Favaloro RG. Idiopathic enlargement of the right atrium. Report of four cases. Am f Cardiol 1969; 23: 278-84.

${ }^{6}$ Houghen TJ, Mulder DG, Gyepes MT, Moss AJ. Aneurysm of the left atrium. Am $\mathcal{F}$ Cardiol 1974; 33: 557-61.

'Krueger SK, Ferlic RM, Mooring PK. Left atrial appendage aneurysm. Correlation of noninvasive with clinical and surgical findings: report of a case. Circulation 1975; 52: 732-8.

${ }^{8}$ Ingram A, Macfie JWS. Two further cases of cardiac aneurysm. Ann Trop Med Parasitol 1922; 16: 119-25.

${ }^{9}$ Eie H, Semb G, Müller O, Holm HA. Aneurysm of the left atrial appendage. Scand $\mathcal{f}$ Thorac Cardiovasc Surg 1972; 6: 149-53.

${ }^{10}$ Williams WG. Dilatation of the left atrial appendage. Br Heart f 1963; 25 : 637-43.

${ }^{11}$ Hall J, Dobbs RH. Cerebral emboli from aneurysm of left atrial appendage. I roc $R$ Soc Med 1969; 62: 911.

${ }^{12}$ Sanderud A, Garman D, Hatle L, Rokseth R. Aneurysmal dilatation of the left auricle. Scand $f$ Thorac Cardiovasc Surg 1971; 5: 143-6.

${ }^{13}$ Parmley LF Jr. Congenital atriomegaly. Circulation 1962; 25: 553-8.

${ }^{14}$ Sloman G, Hunt D, Hare WSC. Aneurysmal dilatation of the left atrial appendage. Med f Aust 1969; 2: 101-2.

${ }^{15}$ Godwin TF, Auger P, Key JA, Wigle ED. Intrapericardial aneurysmal dilatation of the left atrial appendage. Circulation 1968; 37: 397-401.

${ }^{16}$ Palacio J, Guido JJ, Noger VN, Gonnella CG, Villegas Videla AF. Megaorejuela izquierda congenita. Prensa Med Argent 1960; 47: 1505-11.

${ }^{17}$ Behrendt DM, Aberdeen E. Congenital aneurysm of the left atrium. Ann Thorac Surg 1972; 13: 54-9.

Requests for reprints to Dr Jesse E Edwards, Department of Pathology, United HospitalsMiller Division, $125 \mathrm{~W}$ College Avenue, St Paul. Minnesota 55102, USA. 